THE

C H E M I C A L

RE C O R D

\section{Tacrines as Therapeutic Agents for Alzheimers Disease. V. Recent Developments}

\author{
Óscar M. Bautista-Aguilera, ${ }^{\text {[a] }}$ Lhassane Ismaili, $^{[\mathrm{b}]}$ Isabel Iriepa $^{[\mathrm{a}, \mathrm{c}]}$ Daniel Diez-Iriepa, ${ }^{[\mathrm{a}]}$ \\ Fakher Chabchoub, ${ }^{[\mathrm{d}]}$ José Marco-Contelles, ${ }^{*[\mathrm{e}]}$ and Marta Pérez ${ }^{*[\mathrm{f}]}$
}

\begin{abstract}
Herein we have reviewed our recent developments for the identification of new tacrine analogues for Alzheimer's disease (AD) therapy. Tacrine, the first cholinesterase inhibitor approved for $\mathrm{AD}$ treatment, did not stop the progression of $\mathrm{AD}$, producing only some cognitive improvements, but exhibited secondary effects mainly due to its hepatotoxicity. Thus, the drug was withdrawn from the clinics administration. Since then, many publications have described non-hepatotoxic tacrines, and in addition, important efforts have been made to design multitarget tacrines by combining their cholinesterase inhibition profile with the modulation of other biological targets involved in AD.
\end{abstract}

Keywords: Alzheimer's disease, Cholinesterase inhibition, Friedländer reaction, Hepatotoxicity, Tacrine derivatives [a] Ó. M. Bautista-Aguilera, I. Iriepa, D. Diez-Iriepa

Departamento de Química Orgánica and Química Inorgánica. Ctra. Madrid-Barcelona, Universidad de Alcalá, Km. 33, 6, 28871, Madrid, Spain

E-mail: oscar.bautista@uah.es

[b] L. Ismaili

Laboratoire de Chimie Organique et Thérapeutique, Neurosciences intégratives et cliniques EA 481, Univ. Bourgogne Franche-Comté, UFR Santé, 19, rue Ambroise Paré, F-25000 Besançon, France

[c] I. Iriepa

Institute of Chemical Research Andrés M. del Río, Alcalá University, 28805-Alcalá de Henares, Madrid, Spain

[d] F. Chabchoub

Laboratoire de Chimie Appliquée: Hétérocycles, Corps Gras et Polymères, Faculté des Sciences de Sfax, Université de Sfax. B. P 802. 3000 Sfax-Tunisie

[e] J. Marco-Contelles

Laboratory of Medicinal Chemistry (IQOG, CSIC), Juan de la Cierva 3; 28006-Madrid, Spain

E-mail: jlmarco@iqog.csic.es

[f] M. Pérez

Public Health Department, Faculty of Medicine and Nursing,

University of the Basque Country. Leioa, Spain

E-mail: mperez273@ikasle.ehu.eus

\section{Introduction}

Alzheimer's disease $(\mathrm{AD})$ is a progressive neurodegenerative disease, and the most common cause of dementia in the elderly, against which there is no effective treatment to date. ${ }^{[1-4]}$ In the early 1970 s, research was aimed at understanding the biochemical mechanisms involved in $\mathrm{AD}$, establishing the rational basis for the development of a therapy. ${ }^{[5]}$ It was discovered that in $\mathrm{AD}$, the neocortical deficiency of choline acetyltransferase, the enzyme responsible for the synthesis of acetylcholine (ACh), together with the reduction of choline absorption, the decrease in the concentration of $\mathrm{ACh}$ by hydrolysis of cholinesterase enzymes (ChEs), the loss of cholinergic neurons of the Meynert basal nucleus and the reduction in the number of nicotinic and muscarinic ACh receptors, were clear indications that in $\mathrm{AD}$ there was a loss of cholinergic transmission, and that these biological processes were linked to the deterioration of the cognitive abilities of the AD patients, ${ }^{[6-10]}$ setting the principles of the cholinergic hypothesis of $\mathrm{AD}$.

By using synaptic theoretical approaches for central cholinergic enhancement, Summers ${ }^{[11]}$ reported a pilot study in twelve patients with tacrine (1,2,3,4-tetrahydroacridin-9amine), followed by a successful long-term treatment to evaluate the ability of tacrine to improve cognitive defects in 


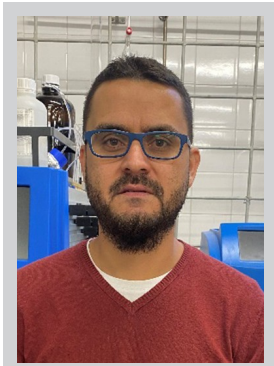

Óscar Bautista-Aguilera received his BSc degree in chemistry from the Universidad del Valle (Colombia) in 2009. Bautista-Aguilera obtained a PhD in organic chemistry from Universidad Autónoma de Madrid (Spain) in 2014 working under the supervision of Prof. José Marco-Contelles (IQOG-CSIC, Spain). He started his career as a Postdoctoral Research Associate at the University of Franche-Comte (France), followed by two postdoctoral research positions at the Université Catholique de Louvain (Belgium). Currently, Bautista-Aguilera is a Postdoctoral Research Associate at the Universidad de Alcalá (Spain), where he was recenlty awarded a prestigious "Atracción de talento" fellowship by the Autonomous Community of Madrid. His research interests focus on medicinal chemistry, synthesis of small multitarget molecules and supramolecular chemistry.

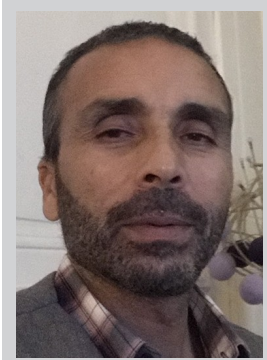

Lhassane Ismaili is a Professor in in the faculty of health sciences at the University of Franche Comte where he has been a faculty member since 2003. He is a Director of studies since 2018. Lhassane teaches several courses on organic and medicinal chemistry, as well as molecular modeling to pharmaceutical and medical students Lhassane Ismaili completed his Ph.D. in the laboratory of medicinal chemistry at University of Franche Comte. His research interests lie in the area of synthesis via multicomponent reactions of new drugs for Alzheimer disease. He collaborates actively with researchers in several other disciplines of biology and biochemistry for the evaluation of the synthesized compounds. He is the author or coauthor of more than 70 papers in international refereed journals and 4 European patents.

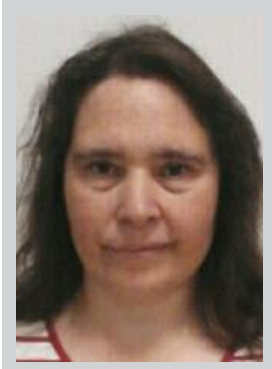

Isabel Iriepa Canalda obtained her PhD in 1989 (University of Alcalá, UAH). This thesis won the Extraordinary Doctorate Award. Postdoctoral Fellow (1989-1990): Duke University in North Carolina (USA), with Prof. Bert Fraser Reid, working on the synthesis of natural products from carbohydrates; Sheffield University, Sheffield (England), in the group of Prof. Fraser Stoddart, working in Supramolecular Chemistry. Currently, she is Associate Professor, at the Organic Chemistry and Inorganic Chemistry Department in UAH. Her research interests are focused on the use of Computational Chemistry for design of new pharmacologically active compounds along with their synthesis and biological evaluation. She have been developing the research work together with Institutional Responsabilities.

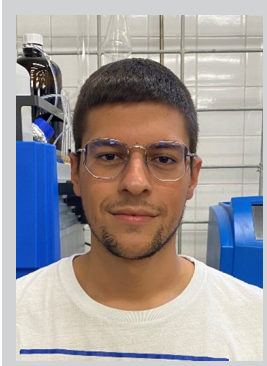

Daniel Diez Iriepa obtained his degree in chemistry in 2017 (University of Alcalá, UAH) with extraordinary award. In 2015 he obtained the scholarship introduction of research from the same university and in 2016 he got the collaboration scholarship from the Spanish Ministery of education, culture and sports. He finished his Master's in science research in 2018 with the scholarship initiation of the research activity from the UAH. Currently he is doing his $\mathrm{PhD}$ in the UAH under the supervision of Dra. Isabel Iriepa Canalda (UAH) and Prof. José MarcoContelles (IQOG-CSIC). He obtained the FPU grant from the UAH (2019) and currently he has an FPU grant from the Spanish Ministry of Science, Innovation and Universities. His thesis is focused on design and synthesis of new small molecules for age related diseases such as Alzheimer or ischemic.

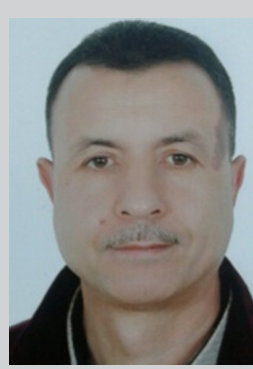

Fakher $\mathrm{CHABCHOUB}$ is a Professor in Organic Chemistry at the department of chemistry in Faculty of Sciences of SfaxTunisia. He obtained a PhD in organic chemistry from University of Sfax (Tunisia) in 1999. Fakher teaches several courses on organic chemistry. His main scientific interests include heterocyclic chemistry (synthesis, characterisation and biological evaluation of molecules)

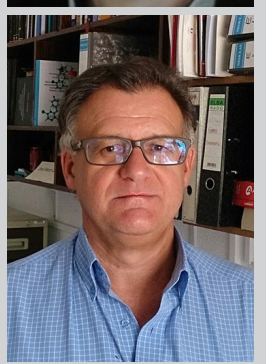

José Marco-Contelles obtained his PhD in 1984 (Complutense University of Madrid, Spain). Postdoctoral Fellow (1984-1986): Institut de Chimie des Substances Naturelles (France); 1986 Département de Chimie Organique, University of Geneva; (1988-1989): Department of Organic Chemistry, Duke University, Durham (USA). Invited Professor: University Pierre and Marie Curie (France), University of Picardie-Jules Verne (France), University of Okayama (Japan), and University Franche-Comté (France). He received 2002 Chemistry French-Spanish, and 2016 Lilly Outstanding OIDD Collaborator awards. Currently, he is Senior Research Scientist, at the Institute of General Organic Chemistry (CSIC). His research interests are focused on the design, synthesis and biological evaluation of new compounds for Alzheimer's disease and stroke.

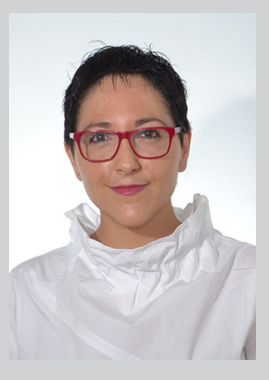

Lda. Marta Pérez Gómez was born in 1982 in Ávila, Spain. She graduated in Pharmacy from the University of Salamanca in 2008. She worked since 2004, in the Department of Pharmaceutical Chemistry to obtain in 2008 the Degree of Salamanca. Since 2008 she has been combining her work as a community pharmacist with research, training and teaching. In 2009 she obtained the Certificate of Pedagogical Aptitude from the Camilo José C ela University (Madrid) and in 2010, the Research Proficiency in Pharmacology from the University of Valladolid. In 2013 he began research work with Prof. José L. MarcoContelles at the Institute of Organic Chemistry in Madrid. Since 2018 he has been working on her PhD in Public Health and Epidemiology, in the Department of Public Health, Faculty of Medicine, UPV/EHU, Leioa, Bizkaia. 
$\mathrm{AD}$ patients. As a result, the first $\mathrm{AChE}$ inhibitor (AChEI) was approved for the treatment of $\mathrm{AD}$, launched to the market under the trade name of Cognex." However, tacrine was later withdrawn due to its hepatotoxic effects, as nearly half of the patients had increased serum alanine aminotransferase, and a smaller percent had severe nausea and vomiting. A second generation of ChEIs was developed in order to avoid the side effects of tacrine. ${ }^{[12]}$

There are currently three ChEIs approved by the US Food and Drug Administration (donepezil, rivastigmine and galantamine), but these drugs neither cure nor stop the progression of AD. Recent studies showed that donepezil has a promising disease-modifying potential due to a decrease of hippocampal atrophy in patients with mild cognitive impairment, compared to placebo. ${ }^{[13]}$ Therefore, a renewed interest for ChEIs, not only for managing the symptoms, but also as promising disease-modifying drugs in $\mathrm{AD}$, was observed, and as a consequence, for new ChEIs based on tacrine with better Absorption Distribution Metabolism Excretion-Toxicity (ADME-Tox) properties.

Very interestingly, AChEIs binding at the Peripheral Anionic Site (PAS) are known to play an important role inhibiting amyloid beta $(A \beta)$ aggregation induced by $A C h E$. In a study carried out by Inestrosa and co-workers ${ }^{[14]}$ the aggregation of the $A \beta$ peptide was simulated for $24 \mathrm{~h}$, and the amount of the aggregated peptide was quantified by measuring the remaining amount of soluble peptide after incubation using a sedimentation test. The addition of AChE led to a 3fold increase in $A \beta_{1-40}$ peptide aggregation compared to the experiment where the peptide was used alone. These tests were carried out using the thioflavin $\mathrm{T}$ (ThT) aggregation assay. The molar ratio between $A \beta_{1-40}$ and $A C h E$ was $100 / 1$ and the test demonstrated that $\mathrm{AChE}$ was a $\mathrm{A} \beta_{1-40}$ aggregation promoter. This study found that AChEIs preferentially binding at the PAS had a greater effect in inhibiting $A \beta$ aggregation.

On the other hand, although the etiology of $\mathrm{AD}$ has not yet been elucidated, $\mathrm{AD}$ is a multifactorial disease, involving several co-occurring processes. Therefore, using a strategy focused on a single drug target is not satisfactory, and the reason why the current efforts to find a therapy for $\mathrm{AD}$ are focused on multitarget small molecules (MSM) to increase the modulation of multiple biological targets, that may improve both therapeutic safety and efficacy. ${ }^{[15-19]}$

Our research group has been developing new MSM for $\mathrm{AD}$, based on tacrines designed by incorporating diverse pharmacophores, with the aim to obtain potential drugs with better ADME-Tox properties. These progresses and results have been reviewed and updated. ${ }^{[20-23]}$ Continuing with this effort, in this account we have reviewed the most recently results carried out in our laboratories during the last decade in the frame of the design and synthesis of non-hepatotoxic tacrines, targeted to bind at specific AChE sites, as single tacrine monomers, or as bivalent inhibitors simultaneously binding at the AChE catalytic anionic site (CAS) and PAS.

\section{Catalytic AChE Site Targeted Tacrines}

A large number of tacrines have been obtained by Lewis acid catalyzed modified Friedländer reaction (FR), starting from suitable $o$-aminonitriles and cycloalkanones. Originally, FR was the acid or base promoted condensation of an aromatic 2amino-substituted carbonyl compound with an appropriately substituted carbonyl derivative containing an reactive $\alpha$-methylene group, followed by cyclodehydration. ${ }^{[24]} o$-Aminonitriles could be installed in aromatic heterocyclic such as quinolines, pyrimidines, quinazolines, quinazolinones, quinazolinediones and other fused nitrogen-containing heterocycles that could have important pharmacological interest. Thus, we have designed new tacrine analogues in which the central core 4aminopyridine, essential for the binding at the CAS of AChE, was maintained, replacing the benzene ring $A$ with a pyridine, quinone, pyran, quinoxaline, and quinoline structural and functional motifs (Figure 1).

\subsection{Pyridotacrines}

Pyridotacrines (PT, I) ${ }^{[25]}$ (Figure 1) are tacrine analogues bearing the 1,8-naphthyridine motif, whose design was inspired by other tacrines that did not present hepatotoxic effects compared to tacrine, such as tacripyrines, a series of potent inhibitors of ChEs, binding preferentially at the PAS of $\mathrm{AChE}$ and therefore able to inhibit $\mathrm{A} \beta$ aggregation, and $\mathrm{Ca}^{2+}$ channel blockers, ${ }^{[26]}$ or the 2-aminopyridine-3,5-dicarbonitriles

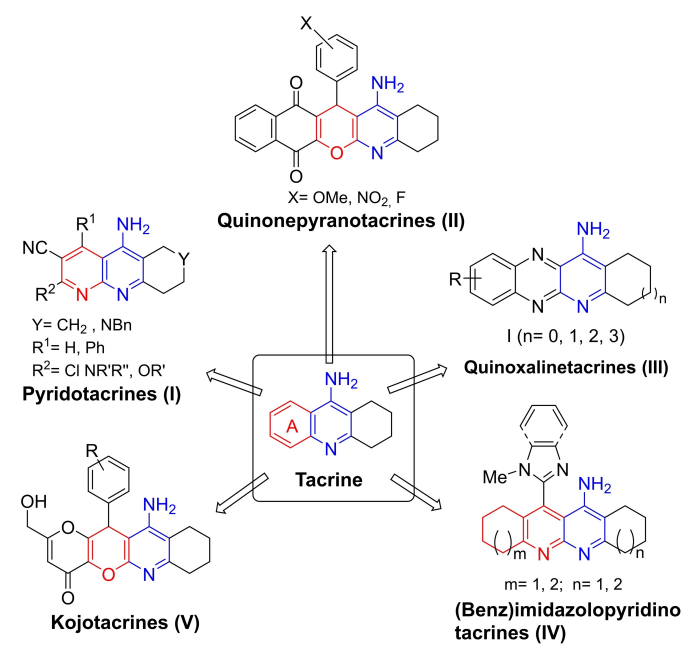

Figure 1. Catalytic AChE site designed tacrines. 
and 2-chloropyridine-3,5-dicarbonitrile, which presented moderate activity against ChEs and neuroprotection, ${ }^{[27]}$ and were used as precursors for the synthesis of PT1-12 (Table 1).

From the $\mathrm{IC}_{50}$ inhibition values (Table 1), it was apparent that all tacrines bearing a chlorine atom at $\mathrm{C}-2$ were poor AChEI, a result in good agreement with the fact that pyridoctacrines bearing electron donating groups at position C-2 showed inhibition of EeAChE in the nanomolar range.

In this study, the authors identified tacrine PT1 (Table 1), as a very potent and selective AChEI, in the nanomolar range. Note that tacrine PT5 (Table 1) only differing from tacrine

Table 1. Synthesis and ChE inhibition of PT1-12.

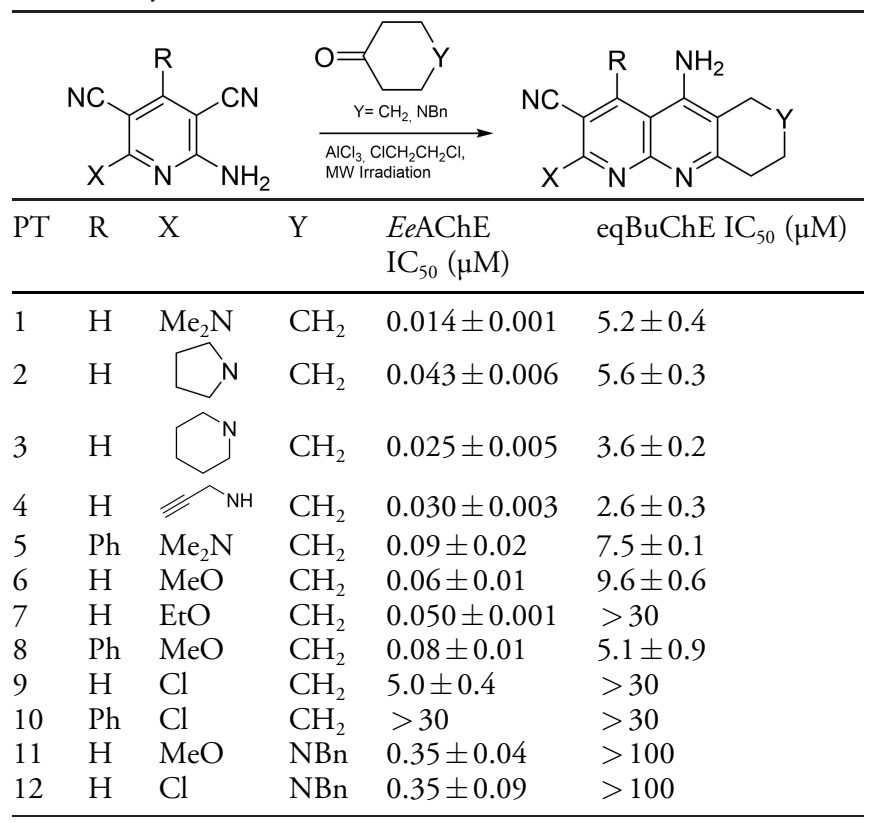

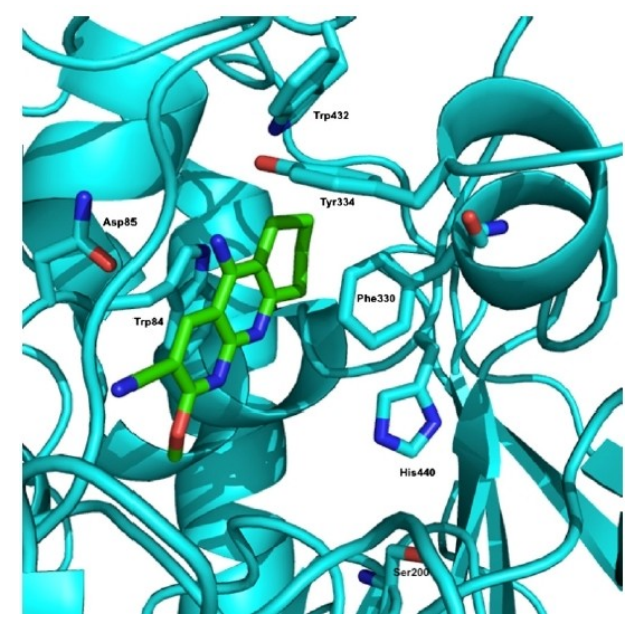

Figure 2. Binding mode of PT6 at the CAS of AChE.
PT1 in the phenyl group at C-4, was less potent than PT1. In spite that tacrine PT6 (Table 1) $\left[\mathrm{IC}_{50}(E e \mathrm{AChE})=0.06 \pm\right.$ $\left.0.01 \mu \mathrm{M} ; \mathrm{IC}_{50}(\mathrm{eqBuChE})=9.6 \pm 0.6 \mu \mathrm{M}\right]$ is a less potent AChEI than PT1, ligand PT6 was obtained in higher chemical yield, exhibited better balance between potency and selectivity, and an inhibition power against EeAChe $(\mathrm{Ki}=69.2 \mathrm{nM})$ in the same order of magnitude as PT1, showing a noncompetitive EeAChE inhibition mechanism.

Molecular modeling showed that tacrines PT1-12 were almost planar compared to tacripyrines, ${ }^{[26]}$ which have an angular geometry because the dihydropyridine ring is bent compared to the pyridine ring of compounds PT1-12. This may explain why these tacrines can enter without restriction and impediment through the binding pocket until getting the CAS of AChE, and therefore not binding at the PAS of AChE. The binding mode of tacrine PT6 at EeAChE was determined by means of a molecular modelling study (Figure 2), using AutoDock 4.0 software, ${ }^{[28]}$ confirming that this ligand, as expected, and similarly to tacrine, binds at the CAS of AChE (Figure 2).

Finally, the neuroprotection ${ }^{[29]}$ capacity of tacrines PT1-12 (Table 1) was determined by using a reactive oxygen species generation model (ROS), based on the cocktail of two mitochondrial respiratory chain blockers, rotenone and oligomycin (R/O), and the hyperphosphorylation model of the tau protein using okadaic acid (OA), a well-known phosphatase inhibitor protein. From these results it was concluded that the neuroprotective profile of these tacrines was moderate, the most potent being tacrines PT2 and PT7 (Table 1), which reduced cell death around $29 \%$. Alike, a study where neuronal death was induced using OA was carried out, showing the effect of PT6 (Table 1) to block or rescue neurons from brain death.

To sum up, tacrines PT1-12 (Table 1) can be considered attractive therapeutic molecules playing key role in cholinergic dysfunction and oxidative stress in the progression of $\mathrm{AD}$.

\subsection{Quinonepyranotacrines}

Racemic quinonepyranotacrines (QPT, II) are tacrine analogues designed by juxtaposition of tacrine and 1,4-napthoquinone (Figure 1), both motifs linked by a $4 H$-pyrane ring, bearing two different electron withdrawing groups $\left(\mathrm{NO}_{2}\right.$ and F) and an electron donating group $(\mathrm{OMe})$ in the aromatic ring located at the central pyran ring. Ten members of this family (QPT1-10) (Figure 3) were prepared from easily available precursors in good overall yield. ${ }^{[30]}$

Possible QPTs hepatotoxicity assay was performed using the human hepatocellular carcinoma cell line (HepG2). ${ }^{[29]}$ This cell line possesses many genetic characteristics, typical of normal liver cells and is an alternative to hepatocytes. HepG2 cells are used for the experimental evaluation of the potential 

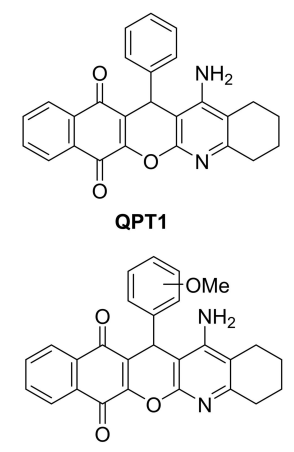

QPT2 X $=2$ '-OMe QPT3 X $=3^{\prime}-\mathrm{OM}$ QPT4 X = 4'-OMe

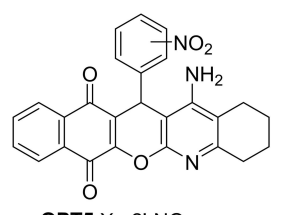

QPT5 X $=2^{\prime}-\mathrm{NO}_{2}$ QPT6 X $=3^{\prime}-\mathrm{NO}_{2}$ QPT7 X $=4-\mathrm{NO}_{2}$

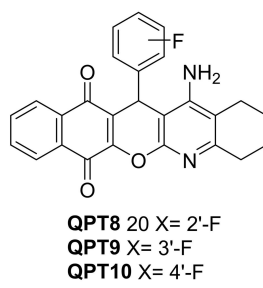

Figure 3. General structure of Quinopyranotacrines (II).

metabolic changes that the liver cells would undergo under the influence of a drug. The use of the HepG2 line allows studying the action of hepatotoxins and drugs, using a multitude of parameters, such as cell viability, proliferation, membrane integrity, to assess toxicity. In this case, an in vitro cell viability test was carried out at five different concentrations (10, 30, $100,300$ and $1000 \mu \mathrm{M})$, using tacrine as a reference. For most QPTs, at $1000 \mu \mathrm{M}$ dose, no significant toxicity was observed, indicating that QPTs are non-hepatotoxic tacrines.

Next, the assessment of the inhibition of ChEs was carried out using the Ellman's test. ${ }^{[31]}$ QPT1-10 showed from moderate to poor human $\mathrm{ChE}(\mathrm{hChE})$ inhibition, the most potent being QPT4 (Figure 3) $\quad\left[\mathrm{IC}_{50} \quad(\mathrm{hAChE})=1.10 \pm\right.$ $0.15 \mu \mathrm{M}]$, selective against $\mathrm{hBuChE}$, and 3.5-fold less hepatotoxic than tacrine at $1000 \mu \mathrm{M}$. The kinetic analysis of hAChE inhibition for QPT4 showed that the LineweaverBurk graph ${ }^{[32]}$ fits into a mixed-type inhibitor behavior with $\mathrm{Ki}$ value of $3.64 \pm 2.06 \mu \mathrm{M}$.

The antioxidant activity was determined by measuring the Oxygen Radical Absorbance Capacity (ORAC test) ${ }^{[33][34]}$. The results were expressed as Trolox/equivalent (TE), indicating the ability of the tested compounds to scavenge peroxyl radicals produced in the test, ferulic acid being used as a positive control. None of the QPTs were more potent than ferulic acid, and according to the structure-activity relationship of the compounds, it was observed that those with electronwithdrawing groups in the para-position of the phenyl group presented the highest antioxidant activity, the most potent antioxidant being QPT10 (3.34 $\pm 0.14 \mathrm{TE})$.
Next, a very detailed docking study the most promising QPT4, using AutoDock Vina software ${ }^{[28]}$ was carried out, in which the docking of each of the enantiomers in hAChE was analyzed. The process of recognizing each of the QPT4 enantiomers with hAChE was done using a novel docking method that considers some key amino acid residues flexible, allowing hAChE to adjust its conformation to the substrate keeping the rest of the enzyme rigid. (R)-QPT4 docking revealed several non-covalent interactions that play an important role in the interaction of QPT4 and the binding pocket of hAChE (Figures 4a-c). A hydrogen bond interaction between the carbonyl oxygen from quinone and the $\mathrm{N}-\mathrm{H}$ of Phe 295 was observed, likewise hydrophobic $\pi-\pi$ stacking interactions between Tyr341 and Trp286 with the fused aromatic systems of the $(\boldsymbol{R})$-QTP4 molecule was also highlighted (Figure 4c). Additionally, $p$-methoxybenzene forms a $\pi-\pi$ Edge to phase interaction with Tyr341. On the other hand (S)-QPT4 interacts with the PAS of hAChE in a similar way that $R$ enantiomer (Figure $4 \mathrm{~b}$ ). The quinone motif facilitates $\pi-\pi$ stacking interactions with the $\operatorname{Trp} 286$ side chain of PAS, likewise the pyridine and the $p$-methoxybenzene fragments provide $\pi-\pi$ stacking interaction with $\operatorname{Trp} 341$. Additionally, the nitrogen of the pyridine facilitates a hydrogen bond interaction with the carboxylate group of Asp74 (Figure $4 \mathrm{~d})$. The most stable conformations generated through docking show that both enantiomers occupy the same spatial region of the PAS from hAChE, but in an inverse orientation, as can be seen in Figures $4 \mathrm{a}$ and $4 \mathrm{~b}$. However, the binding energy of both QPT4 enantiomers reveal that the $R$ enantiomer $(-12.4 \mathrm{Kcal} / \mathrm{mol})$ exhibits lower binding energy than $S$ enantiomer $(-10.4 \mathrm{Kcal} / \mathrm{mol})$ when they interact with the binding site of hAChE.

Lastly, ADME-Tox calculations were carried out with the aim of measuring pharmacokinetic properties of all enantiomers of QPTs. Overall, most of molecules presented optimal pharmacokinetic properties and fit well with what the theory predicts for drugs that act in the CNS, however, QPT4 (Figure 3) presented a Polar Surface Area (PSA) value of approximately $100 \AA^{2}$ for each enantiomer. The PSA value for drugs that are going to act in the CNS should not exceed $60 \AA^{2}$. Likewise, this study evaluated the ability of QPT1-10 to cross the blood-brain barrier (BBB), a fundamental criterion that a drug should meet in order to act in the central nervous system (CNS), showing that QPT4 was predicted to cross the $\mathrm{BBB}$, being permeable with a penetration estimation $(\mathrm{Pe})$ of $4.4 \pm 0.9$, this value being within the Pe range of tacrine and donepezil, two reference drugs known for their ability to cross the BBB. 

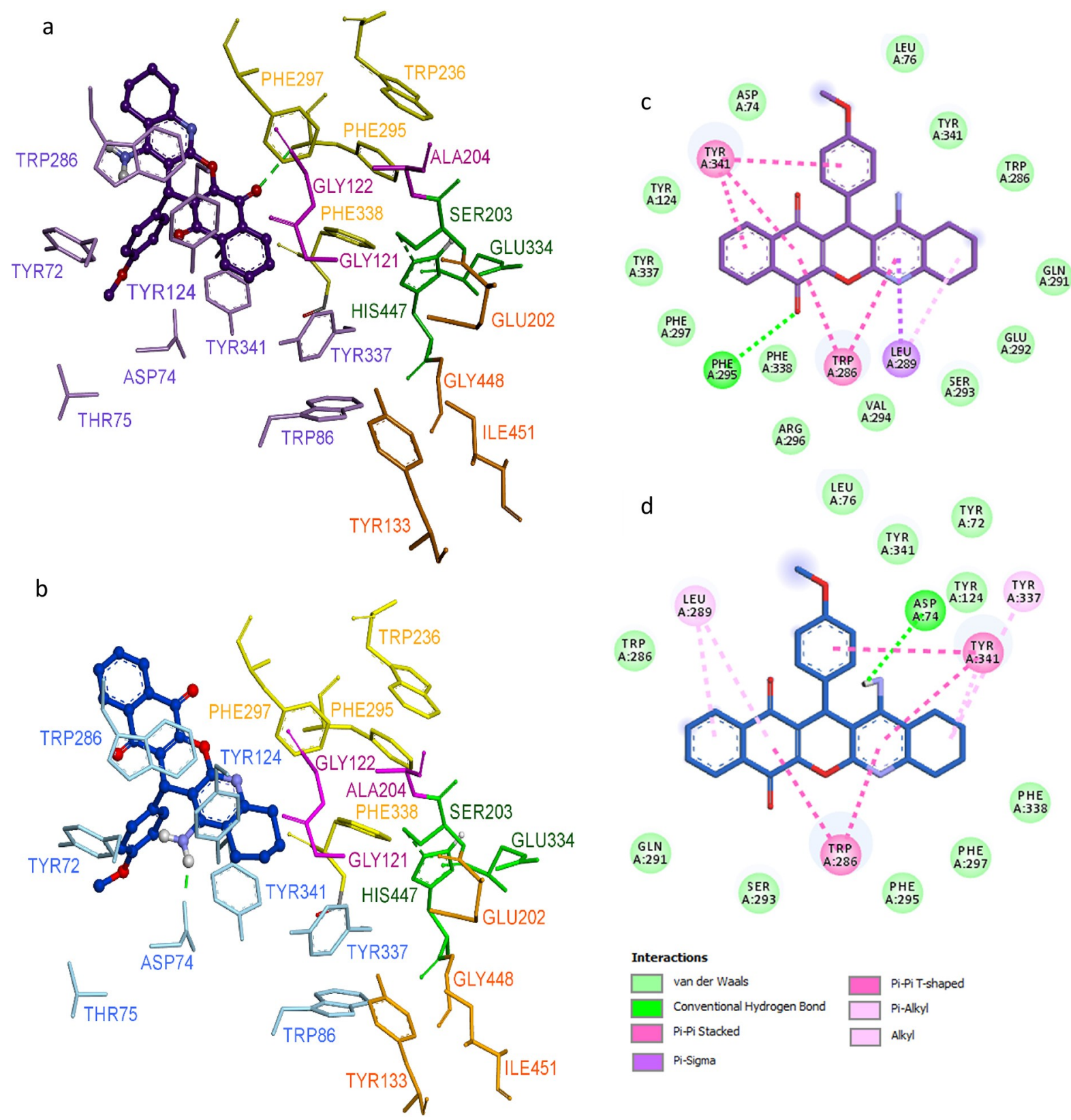

Figure 4. Binding mode of the inhibitors $(\boldsymbol{R})$-QPT4 and (S)-QPT4 within the active site of hAChE. a) $(\boldsymbol{R})$-QPT4 is rendered as ball and sticks (carbon atoms in purple) b) (S)-QPT4 is rendered as ball and sticks (carbon atoms in dark blue). The side chain conformations of the mobile residues are illustrated in the same light color as the ligand, catalytic triad residues (CT) in green, oxyanion hole residues $(\mathrm{OH})$ in magenta, anionic sub-site (AS) in orange, except Trp86, acyl binding pocket (ABP) in yellow and PAS in the same color as flexible residues. c) 2D interaction map of compound (R)-QPT4 d) 2D interaction map of compound (S)-QPT4.

\subsection{Quinoxalinetacrines}

The aim of this study was the synthesis and biological evaluation of Quinoxalinetacrines (QTs, III) (Figure 1) as new non-hepatotoxic and neuroprotective tacrine analogues, resulting from the juxtaposition of quinoxaline and tacrine, and particularly the analysis of QT78 (Scheme 1), the most simple member of this family. ${ }^{[35]}$

The synthesis of QT78 has been carried out by the reaction of 3-amino-2-quinoxalinecarbonitrile and cyclohexanone, using Lewis acid $\mathrm{AlCl}_{3}$ as catalyst, under typical FR conditions, in $88 \%$ yield (Scheme 1). 


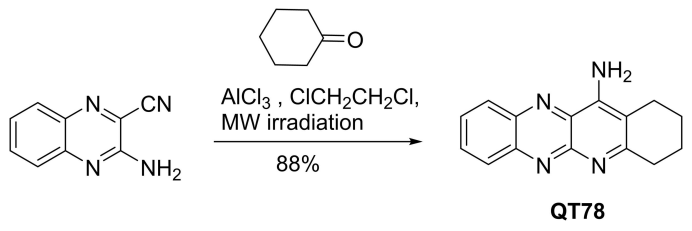

Scheme 1. Synthesis of QT78.

The in silico study of the toxicity ${ }^{[36]}$ showed that there was not enough evidence to predict an adverse outcome of the toxicity of QT78 and its metabolites. However, a cell viability study was performed in the HepG2 cell line to measure in vitro hepatotoxicity of QT78. The results showed that at high concentrations of QT78 (300 to $1000 \mu \mathrm{M})$ cell viability decreased, but hepatotoxicity was significantly lower compared to tacrine, which showed a decrease in cell viability even at much lower concentrations $(30 \mu \mathrm{M})$.

Regarding the inhibition of ChEs, QT78 was a modest but selective inhibitor of $\mathrm{BuChE} \mathrm{IC}_{50}(\mathrm{hAChE})=22.0 \pm 1.3 \mu \mathrm{M}$, and $\left.\mathrm{IC}_{50}(\mathrm{hBuChE})=6.79 \pm 0.33 \mu \mathrm{M}\right]$ and less potent than tacrine.

The docking study on AChE [28] showed that QT78 (Figure 5a) fits well in the middle of the active site gorge without interacting with the catalytic triad amino acids. The cyclohexane ring is directed towards the bottom of the gorge, establishing $\pi$-alkyl interaction with $\operatorname{Trp} 86$. The target-ligand complex is also stabilized by molecular interactions with some amino acid residues of the PAS. Likewise, a hydrogen bond network is established between the amino group and pyrazine nitrogen ring from QT78 with Tyr124 and Asp74. Additionally, the phenyl ring forms $\pi-\pi$ stacking interaction with Tyr341. Nevertheless, the docking with hBuChE showed that QT78 fits inside of CAS (Figure 5b), but it does not occupy the same space as tacrine. According to the docking data, the amino group of QT78 forms two hydrogen bond interactions with the catalytic triad residues His438 and Ser198. In addition, the pyridine and cyclohexane rings interact with residues in the acyl binding pocket (ABP) Phe329 and Leu286. All these molecular modeling results on the two enzymes are complemented with experimental inhibition in ChEs shown by QT78 as a moderate hBuChE selective ChEI.

In silico analysis of the pharmacokinetic properties of QT78 gave a satisfactory result based on the values of the Lipinski's rule for drugs that act on the CNS. ${ }^{[37]}$ It should be bore in mind that Lipinski's rule values for drugs acting on the $\mathrm{CNS}$ are more restricted compared to the other drugs that do not act on the CNS. In the case of QT78, these values are molecular weight $<450 \mathrm{~g} \mathrm{~mol}^{-1}$, hydrogen bond donor $<3$, and hydrogen bond acceptor $<7$. Besides, the aqueous solubility (QPlogS $=-3.746)$ is between $(-6.5$ to -0.5$)$, while the partition coefficient $(\mathrm{Q} \log \mathrm{Po} / \mathrm{W}=2.534)$ indicates

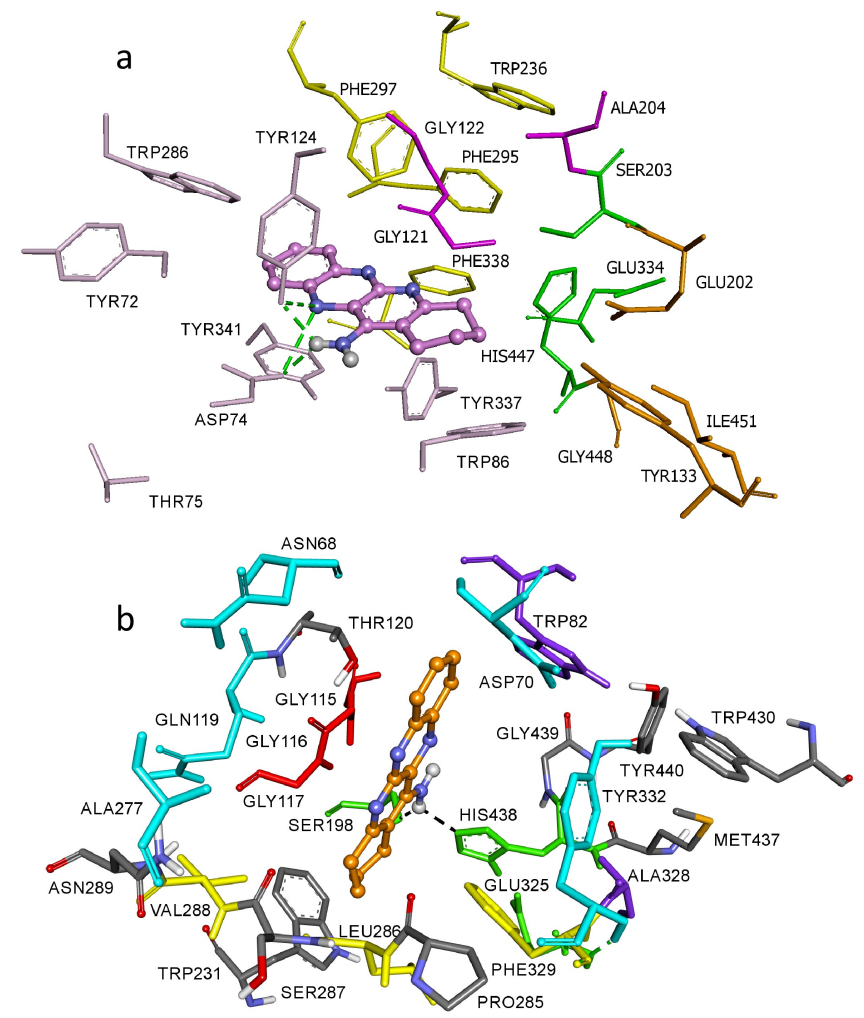

Figure 5. Molecular modeling for compound QT78. a) Binding mode of QT78 in AChE binding-site. Ligand is rendered as ball and sticks (carbon atoms in pink) and the side chain conformations of the mobile residues are illustrated in light pink, $\mathrm{CT}$ in green, $\mathrm{OH}$ in magenta, AS in orange, except Trp86, ABP in yellow and PAS in light pink. b) Binding mode of QT78 (orange) and tacrine (cherry) within the BuChE binding-site. Catalytic anionic site (CAS) in green, $\mathrm{OH}$ in red, choline binding site in violet (CBS), $\mathrm{ABP}$ in yellow, and PAS in blue. Hydrogen bonding interactions were showed in dashed lines.

a good absorption of QT78 in the body since it is in the optimal range of $(-2.0$ to -6.5$)$. QPLogBB value is -0.332 which would indicate that the QT78 could easily penetrate the $\mathrm{BBB}$ since its optimal range is (-2.0 to 1.04). Another important value to take into account is the PSA, which is defined as the area of a molecule's van der Waals surface that arises from the oxygen, nitrogen or hydrogen atom attached to oxygen or nitrogen atoms. For drugs that are going to act in the CNS, PSA must not exceed $60 \AA^{2}$. In the case of QT78 this value is $59.549 \AA^{2}$. PSA is commonly used in medicinal chemistry as a metric for the optimization of cell permeability. Molecules with a PSA greater than $140 \AA^{2}$ are usually believed to be poor at permeating the cell membrane.

Finally, regarding the neuroprotection, QT78 produced a significant increase in cell viability against $\mathrm{R} / \mathrm{O}, 16.7 \%$ and $21.4 \%$, respectively, and a powerful increase in cell viability against OA (18.9\%). In all cases, when increasing the 
concentration of the compound to $1 \mu \mathrm{M}$, the protective capacity decreased against all the toxic stimuli tested.

To sum up, in the search for new non-hepatotoxic tacrines for AD, QT78 was identified as a promising compound, as it is less toxic than tacrine at high concentrations $(100 \mu \mathrm{M}$ to $1 \mathrm{mM}$ ), a selective BuChEI, exhibiting significant neuroprotective effect against different toxic stimuli, including ROS generation and hyperphosphorylation of tau protein.

\section{4. (Benz)imidazolopyridinotacrines}

(Benz)imidazolopyridinotacrines (IV) (Figure 1) are two new families of tacrines designed by incorporating a 2-(1-methyl$1 H$-imidazolyl) (IVa) (Figure 6), or 2-(1-methyl-1 $H$-benzimidazolyl) (IVb) (Figure 6) at C8, and a cycloalkane at C-6/C-7, into tacrine scaffold, and prepared from readily available precursors using the FR to build the tacrine motif. ${ }^{[38]}$

These new tacrine analogues were evaluated by analysing their cytotoxicity in human hepatocellular carcinoma cells and measuring the inhibition of ChEs, along with their antioxidant capacity.

The new tacrines were in general non-hepatotoxic at high doses, potent and selective EeAChEIs, but poor antioxidant agents. Among them, 12-(1-methyl-1H-imidazol-2-yl)2,3,4,7,8,9,10,11-octahydro-1H-benzo[b]cyclohepta[g] $[1,8]$ naphthyridin-13-amine (IPT) (Figure 6) is non-hepatotoxic and selective EeAChE inhibitor $\left(\mathrm{IC}_{50} \quad E e \mathrm{AChE}=0.50 \pm\right.$ $0.03 \mu \mathrm{M}){ }^{[38]}$

\subsection{Kojotacrines}

Racemic kojotacrines (KTs, V, Figure 1) are new tacrine analogues designed by combining antioxidant kojic acid (KA) and tacrine, in our search for new non-hepatotoxic tacrines for AD. ${ }^{[39]}$ Therefore, the known properties of tacrine and the recognized antioxidant characteristics of $\mathrm{KA}$ as a natural fungal metabolite able to sequester ROS, endowed the new KT hybrids with potential $\mathrm{ChE}$ inhibition plus antioxidant capacity.

The synthesis of these KTs was carried out in two steps using the readily available KA, that was reacted with a selection

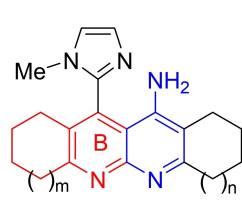

IVa $(\mathrm{m}=1,2 ; \mathrm{n}=1,2)$
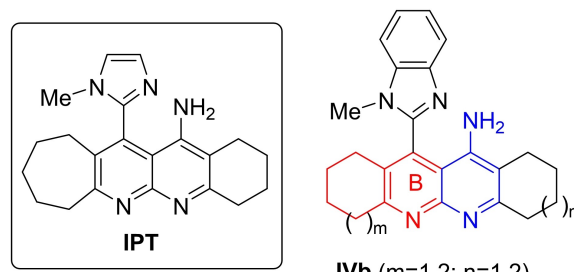

IVb $(m=1,2 ; n=1,2)$
Figure 6. Structure of (benz)imidazolopyridinotacrines (IVa, b) and tacrine IPT. of arylidenemalonitriles in the presence of trimethylamine, in good yields, followed by FR with cyclohexanone, under the usual experimental conditions resulting in the expected racemic mixture. ${ }^{[39]}$ KTs were substituted at different positions, with diverse type of substituents, at the aromatic ring.

The biological evaluation of these KTs included: (1) In vitro cytotoxicity in HepG2 cells, by analysis of the cell viability at different concentrations; most of the KTs are less hepatotoxic than tacrine at $1000 \mu \mathrm{M}$, and among them, KT1 (Figure 7) was 6-fold less hepatotoxic than tacrine. (2) The inhibition of EeAChE and eqBuChE; all the KTs are moderate, but selective AChEIs, less potent than tacrine, KT2 being the most potent EeAChEI $\left(\mathrm{IC}_{50}=0.64 \pm 0.006 \mu \mathrm{M}\right)$, 20-fold less potent than tacrine. (3) The evaluation of antioxidant capacity; KT1 and KT3 (Figure 7) bearing a methoxy group at $\mathrm{C} 2$, and two chlorine atoms at positions $\mathrm{C} 2$ and $\mathrm{C} 6$, respectively (Figure 7), were the most powerful antioxidants $\left[\mathrm{R}=2-\mathrm{OCH}_{3}(6.05 \pm 0.41 \mathrm{TE})\right.$ and $\mathrm{R}=2,6$-di$\mathrm{Cl}(6.14 \pm 0.40 \mathrm{TE})]$. However, KT2 was the most balanced KT considering its hepatotoxicity, neuroprotection, cytotoxicity and ChE inhibition. (4) Neuroprotection. Cell viability of neuroblastoma SH-SY5Y cells treated with the different concentration of KTs incubated for $24 \mathrm{~h}$ was, showed that KT2 had similar neuroprotection against $A \beta_{1-40}$ insult at 3 and $10 \mu \mathrm{M}$, being less neuroprotective than KA.

Taking into account these results, KT2 was selected for docking analysis using Autodock Vina to justify its binding properties at hAChE. Molecular modeling was carried out on the two enantiomers of KT2 (Figure 8). For compound $(\boldsymbol{R})$ KT2, an hydrogen bond was established between Tyr124-OH and the nitrogen atom of the pyranotacrine portion (Figure $8 \mathrm{a}$ ). For compound $(\boldsymbol{S})$-KT2, the amino group establishes a hydrogen bond interaction with the Asp74 carboxylate group (a key residue of PAS), and the oxygen atom of the methoxy group establishes a hydrogen bond interaction with the main chain - NH- group of Thr75 (Figure 8b). As shown in

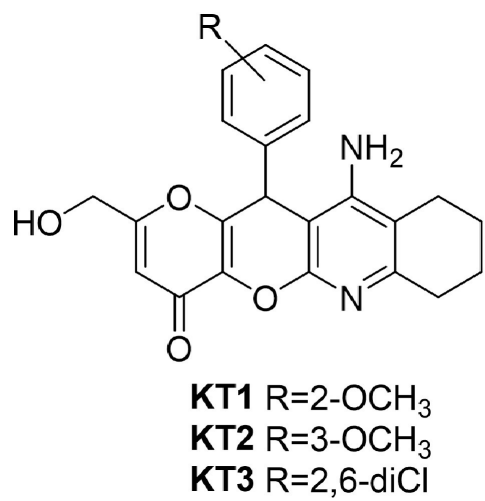

Figure 7. Structure of KT1-3. 

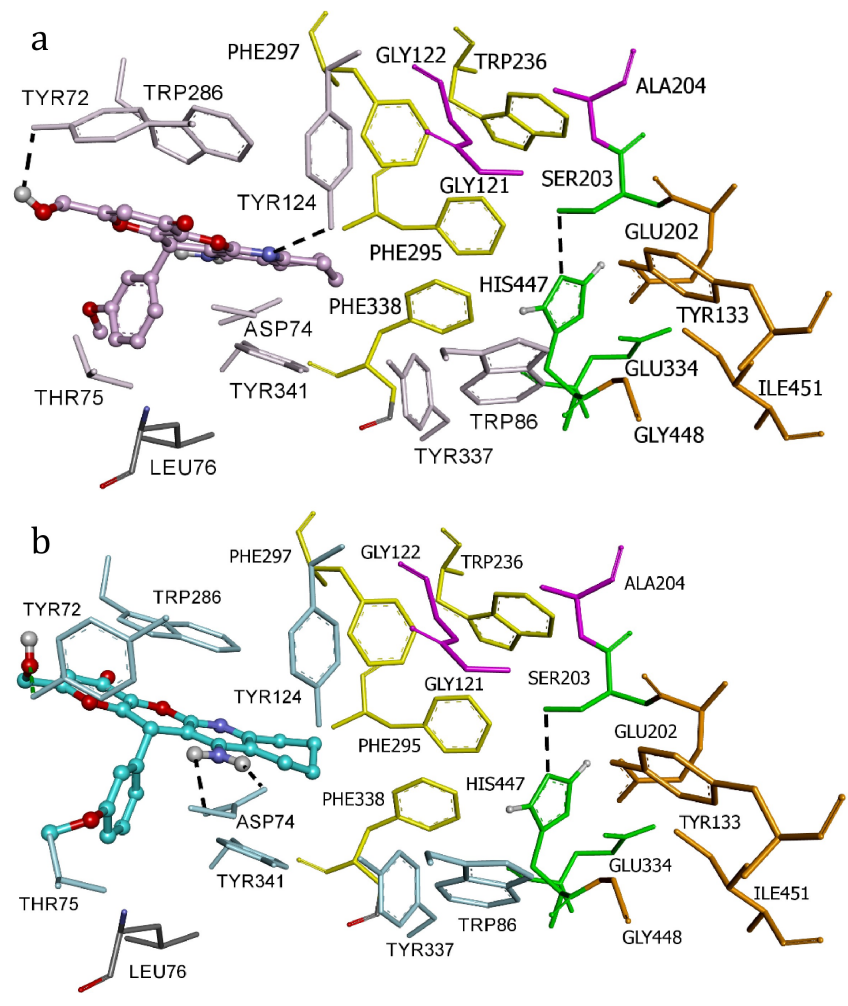

Figure 8. Docking pose of inhibitors $(R)-\mathrm{KT} 2$ and $(S)$-KT2 at the active site of hAChE. a) (R)-KT2 is rendered as ball and sticks (carbon atoms in pink) b) (S)-KT2 is rendered as ball and sticks (carbon atoms in blue). Hydrogen bonds were showed in black dashed lines.

Figure 8 , both enantiomers display hydrogen bond interactions with residue Tyr72 and are positioned on the active site of the enzyme in a manner that interacts with amino acids at the edge of the cavity, they act as a barrier to the substrate for entering the active site.

In silico analysis of ADME-Tox properties was carried out using the QiKProp module of Schrodinger suite in order to evaluate the drug-likeliness of the synthesized KTs. The calculated ADME-Tox properties were in line with the parameters required by the Lipinski's rule for drugs to be used for the CNS. However, molecule KT2 had a PSA of $107 \AA^{2}$ for each enantiomer, much higher than the required value of less than $60 \AA^{2}$ required for drugs acting in the CNS.

Overall, ligand KT2 is a moderate EeAChI in the submicromolar range, presenting neuroprotective and antioxidant activity, 6-fold less hepatotoxic than tacrine, and consequently, a potential new hit for further investigation for $\mathrm{AD}$ therapy.

\section{Bivalent Tacrines}

New and potent AChEIs have been identified by using the "bivalent ligand strategy", that consists of the design of single ligands able to bind simultaneously the CAS and PAS of AChE ${ }^{[40,41]}$ In the first reported example, for instance, two tacrine units were linked by a seven methylene spacer to bind both the CAS and PAS, resulting in the bivalent AChEI bis (7)-tacrine, which showed enhanced affinity toward AChE compared to tacrine. ${ }^{[42]}$

\subsection{Tacrine-ferulic Acid Hybrids}

As mentioned before, the drug discovery approach for $\mathrm{AD}$ therapy based on the $\mathrm{MSM}^{[15,16]}$ strategy involves the incorporation of different pharmacophores from various reference molecules in the same structure to obtain a hybrid molecule, where each pharmacophore retains its capacity for acting in a specific manner and producing the desired pharmacological response, or even better, generate a synergetic effect as a result of the combination of these active components. Accordingly, multicomponent reactions, ${ }^{[43]}$ such as Ugi reaction, ${ }^{[44]}$ are perfect for the MSM strategy, since several active fragments can be coupled in a single reaction and form a unique multipotent molecule.

By following the MSM strategy for AD, tacrine-ferulic acid hybrids (VI, TFAHs) (Figure 9) ${ }^{[17]}$ were designed showing strong antioxidant power, reversible non-competitive AChE inhibition, being capable of binding both PAS and CAS.

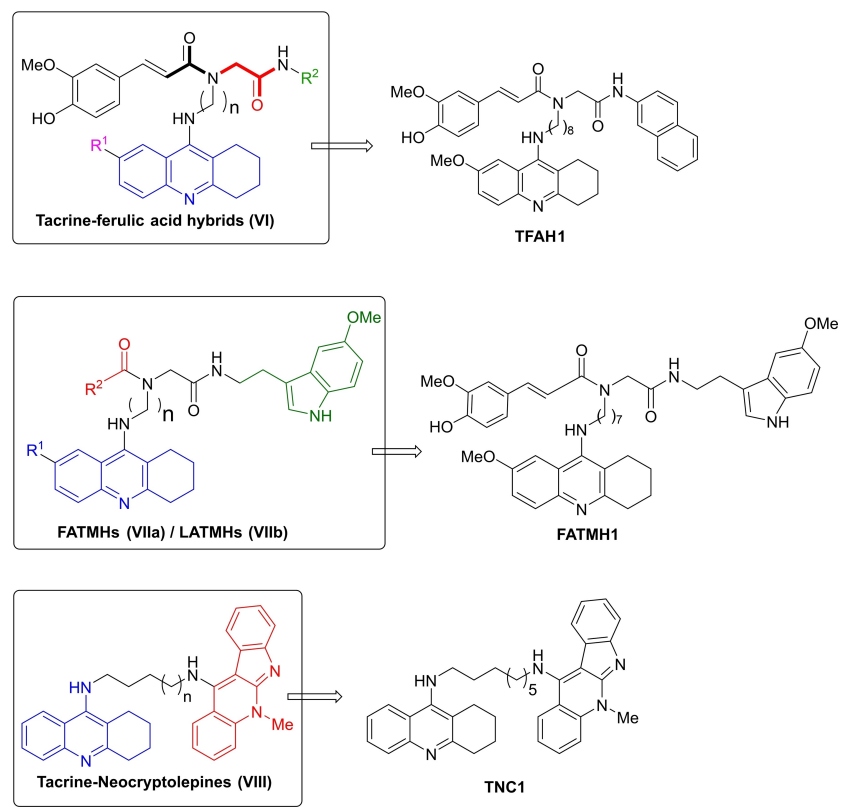

Figure 9. Bivalent tacrine hybrids VI-VIII. 
These compounds bear a substituted glycine substructure as part of the main structure of $\alpha$-acylaminocarboxamide, tacrine or 7-methoxytacrine motifs and an antioxidant feruloyl group, both attached to the glycine fragment. The carbonyl group of the glycine moiety appears as a $N$-benzylamide, $2^{\prime}$-chloro- 6 'methylaniline, or $2^{\prime}$-naphthylamine, functional groups that should provide the ChE inhibitory activity, binding at the hydrophobic PAS of AChE, with possible consequences on $\mathrm{A} \beta$ aggregation.

The synthesis of the new tacrines has been carried out starting from readily available precursors, using the Ugi reaction, which involves the condensation of four reaction components (aldehyde, amine, carboxylic acid, isocyanide). ${ }^{[4]}$ Thus, this reaction would allow the rapid one-step synthesis of $\alpha$-aminoacyl amide derivatives containing different fragments, incorporating for instance, neuroprotective, antioxidant properties, along with capacity of inhibiting ChEs and the aggregation of $A \beta_{1-42}$, important biological targets in the fight against $\mathrm{AD}$.

As a result of the biological evaluation, the authors identified TFAH1 (Figure 9) as a particularly interesting multipotent compound that shows moderate and completely selective inhibition of $\mathrm{hBuChE}\left(\mathrm{IC}_{50}=68.2 \mathrm{nM}\right)$, strong antioxidant activity $(4.29 \pm 0.19 \mathrm{TE})$, good $\mathrm{A} \beta$ anti-aggregation properties $(65.6 \pm 0.9 \%$ at $1: 1$ ratio), able to cross $\mathrm{BBB}$, as determined by PAMPA-BBB assay, low hepatotoxicity $(59.4 \pm 4.7 \%$ cell viability at $1000 \mu \mathrm{M})$, good neuroprotection against toxic insults such as $A \beta_{1-40}, A \beta_{1-42}, H_{2} O_{2}$, and $O / R$ on SHSY5Y cells, at $1 \mu \mathrm{M}$.

It was clear that TFAH hybrids can act as particularly interesting multipotent compounds for the potential $\mathrm{AD}$ therapy.

\subsection{Tacrine-melatonin Hybrids}

Melatonin is a powerful antioxidant natural product that has been used in a number of drug discovery projects to build new molecules for the potential treatment of neurodegenerative diseases. ${ }^{[45]}$ With this idea in mind, new melatonin-tacrine hybrids have been investigated ${ }^{[46]}$ incorporating the hypothesis and concept that "two better than one" regarding the drug design. Thus, the authors have used, in addition to melatonin, typical ferulic or lipoic acid ${ }^{[17][47]}$ as antioxidants, leading to ferulic acid and melatonin tacrine hybrids (FATMHs, VIIa) (Figure 9), and lipoic acid and melatonin tacrine hybrids (LATMHs, VIIb) (Figure 9), whose synthesis has carried out in good yields, as a mixture of their non-separable $E / Z$ rotamers, using Ugi reaction as the key step (Scheme 2).

As a result of the corresponding extensive biological evaluation, hybrid FATMH1 (Figure 9) was identified as a very powerful ChEI $\left[\mathrm{IC}_{50}(E e \mathrm{AChE})=8.37 \pm 0.08 \mathrm{nM} ; \mathrm{IC}_{50}\right.$ $(\mathrm{eqBuChE})=2.91 \pm 0.35 \mathrm{nM}]$, strong antioxidant $(9.11 \pm$

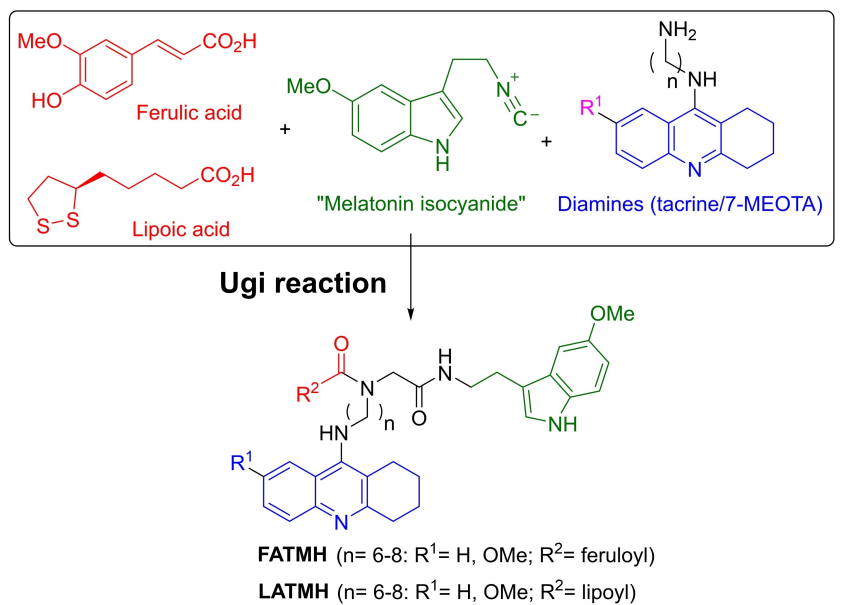

Scheme 2. Synthesis of compounds of type FATMHs (VIIa) and LATMHs (VIIb).

$0.21 \mathrm{TE}$ ) and likely to penetrate the BBB via passive diffusion. Furthermore, this tacrine presented the best neuroprotection values against the exposed toxic insults $\left(\mathrm{H}_{2} \mathrm{O}_{2} 300 \mu \mathrm{M}, \mathrm{A} \beta_{1-40}\right.$ and $\left.A \beta_{1-42} 30 \mu \mathrm{M}\right)$ at $1 \mu \mathrm{M}$ dose and was able to significantly induce the nuclear factor (erythroid-derived 2)-like 2 activators transcription pathway at the concentration of $3 \mu \mathrm{M}$ in AREc32 cells, while less hepatotoxic than tacrine.

\subsection{Tacrine-neocryptolepine Heterodimers}

The bivalent ligand strategy ${ }^{[40-42]}$ has been used for the synthesis and biological evaluation of tacrine-neocryptolepine heterodimers (TNC, VIII, Figure 9$)^{[48]}$ to define potent tacrine analogues, combining in one ligand tacrine and neocryptolepine, an alkaloid isolated from the roots of Cryptolepis sanguinolenta ${ }^{[49]}$ a plant found in Central and Western Africa. The authors envisioned that the tacrine motif should bind the CAS, while the fully planar aromatic neocryptolepine motif would establish appropriate interactions at the PAS of AChE, resulting in more potent AChEIs than tacrine alone.

As a result of the biological evaluation, TNC1 (Figure 9) turned out to be a highly potent hChEI, which can be highlighted among the most potent hAChEIs identified so far $\left(\mathrm{IC}_{50} \mathrm{hAChE}=0.95 \pm 0.04 \mathrm{nM}\right)$, being also a potent $\mathrm{hBuChE}$ inhibitor $\left[\mathrm{IC}_{50}(\mathrm{hBuChE})=2.29 \pm 0.14 \mathrm{nM}\right]$. On the other hand, ligand TNC1 presented higher or similar hepatotoxic levels as tacrine. However, considering that the compound was two orders of magnitude more potent than tacrine as AChEI, one would expect the required dose to be lower than in the case of tacrine, which would lead to lower risk of toxicity.

Molecular modelling was carried out using AutoDockVina. To corroborate the flexibility during coupling, flexible torsion was left in the ligand and the dihedral angles rotated freely. 
Compound TNC1 (Figures 10a and 10b) proved to be a dual inhibitor interacting with both CAS (tacrine residues) and PAS (the indoloquinoline unit of neocryptolepine), justifying and supporting the initial hypothesis about the use of a planar aromatic neocryptolepine to reach and bind the PAS, giving these compounds a high inhibitory power on AChE.

ADME-Tox properties were either predicted using the QikProp module from the Schrodinger suite or analyzed with the appropriate assays for molecule TNC1, that fulfilled the necessary requirements to be considered a potential CNS drug. The molecule showed values of solubility within limits and
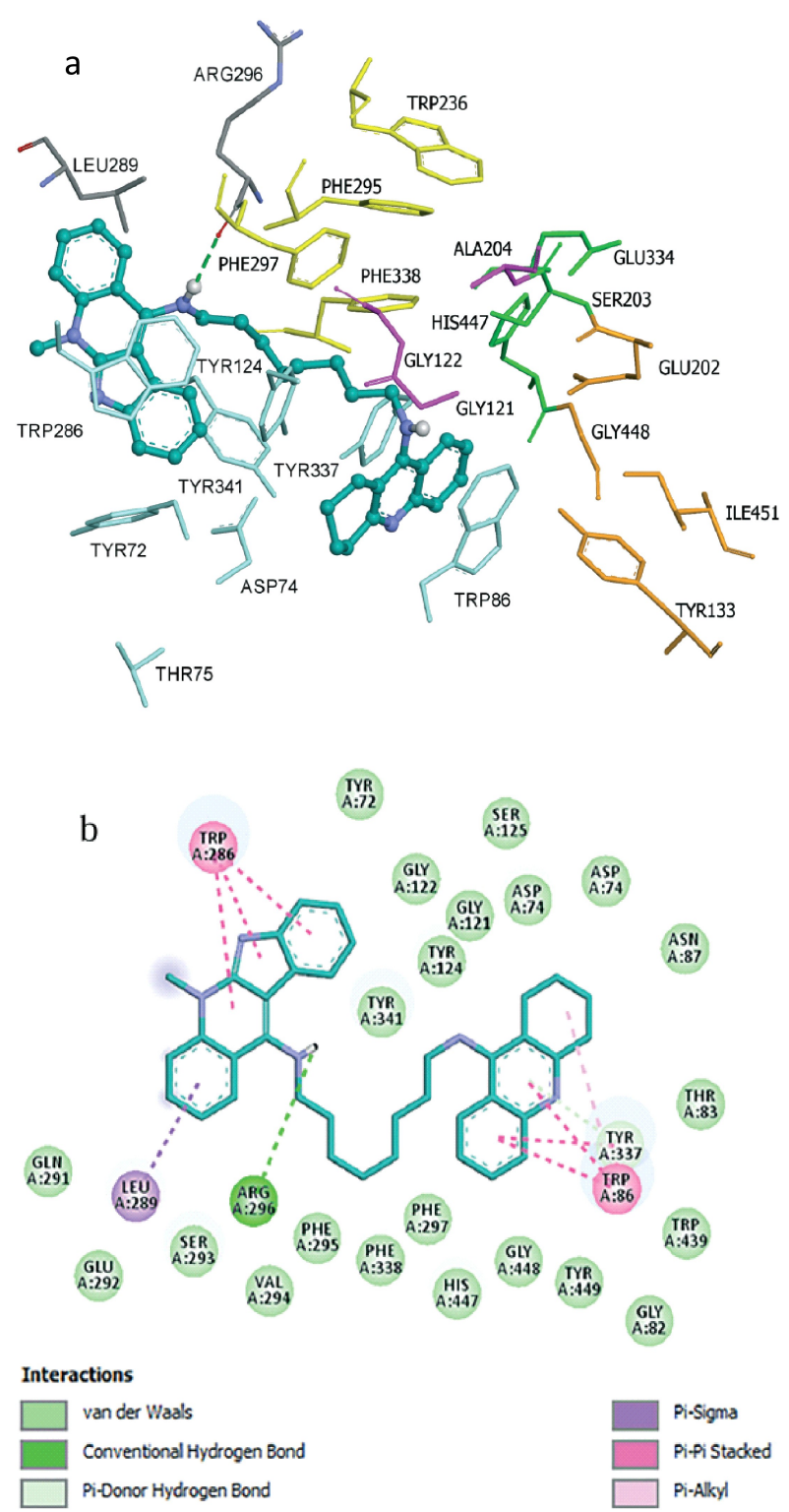

Figure 10. a) Docking pose of compound TNC1 into hAChE. Ligand is rendered as ball and sticks (carbon atoms in dark green). b) Schematic representation of different interactions of compound TNC1 with hAChE. $\log \mathrm{BB}$ values close to or even greater than 0.3 , indicating an excellent potential to traverse the BBB. Regarding the PSA, TNC1 showed a value around $45 \AA^{2}$, which confirms a good penetration into the CNS, and good oral absorption.

\section{Conclusions and Outlook}

Since AD is a multifactorial disease, there is an urgent need for designing MSMs able to interact with multiple therapeutic targets involved the pathology. These new molecular entities should be safe, able to easily overpass the BBB, have neuroprotective and antioxidant capabilities and drug-like properties, as well as the ability to interact with other biological targets involved in $\mathrm{AD}$. The studies presented in this review were developed in the framework of the MSM strategy, by designing non-hepatotoxic tacrines, or at least with less hepatotoxic effects than tacrine itself.

Among all the tacrines shown here, it is worth mention that tacrine IPT (Figure 6) pertaining to the (benz)imidazolopyridinotacrine group (IV, Figure 1) ${ }^{\left[{ }^{[3]}\right]}$ and kojotacrine KT2 (Figure 7$)^{[39]}$ were the compounds with the best nonhepatotoxic profile in the in vitro cell viability assay that uses the HepG2 cell line, being 6- or 7-fold less hepatotoxic, respectively, than tacrine. Conversely, molecule TNC1 (Figure 9) of the tacrine-neocryptolepine heterodimer group was the only one presenting hepatotoxic levels higher or similar to tacrine. Despite this unwanted hepatotoxic effects, ligand TNC1 was the most potent ChEI among all tacrines presented in this review $\left[\mathrm{IC}_{50}(\mathrm{hAChE})=0.95 \pm 0.04 \mathrm{nM}\right.$; $\mathrm{IC}_{50}(\mathrm{hBu}-$ $\mathrm{AChE})=2.29 \pm 0.14 \mathrm{nM}$.

Among the tacrine-ferulic acid hybrids group, tacrine TFAH1 (Figure 9) was the most potent AChEI [ $\mathrm{IC}_{50}$ $\left.(\mathrm{hAChE})=22.2 \pm 1.6 \mathrm{nM} ; \mathrm{IC}_{50}(\mathrm{hBuChE})=68.2 \pm 3.9 \mathrm{nM}\right]$, showing also interesting neuroprotective capacity, which was roughly similar to that tacrine FATMH1 (Figure 9) of the ferulic acid-tacrine-melatonin hybrid family, a AChEI and BuChEI, 60-fold and 3.4-fold, respectively, less potent than tacrine. Another significant property of molecule TFAH1 (Figure 9) is its high $A \beta_{1-42}$ inhibition percentage in the ThT assay $(65.6 \%)$.

Regarding the antioxidant activity, measured with the ORAC test, most of the tacrines shown here presented good antioxidant activity respect to controls. Tacrine FATMH1 (Figure 9) showed the highest antioxidant power (9.11 $0.21 \mathrm{TE}$ ), although molecule TFAH1 (Figure 9) was also very potent $(4.29 \pm 0.19 \mathrm{TE})$.

Last but not least, the in silico ADME-Tox properties of the tacrines reviewed here were in line with the parameters required by the Lipinski's rule for drugs to be used for CNS therapies. Thus, most of the tacrines overpassed the BBB. Accordingly, the experimental BBB penetration estimation, 
measured in a PAMPA assay, showed that tacrines QPT4 Figure 3) (Pe: $4.4 \pm 0.910^{-6} \mathrm{cms}^{-1}$ ), TFAH1 (Figure 9) of the TFAHs group (Pe: $61.5 \pm 4.5 \quad 10^{-6} \mathrm{cms}^{-1}$ ) and FATMH1 (Figure 9) (Pe: $4.4 \pm 0.810^{-6} \mathrm{~cm} \mathrm{~s}^{-1}$ ), are permeable molecules. For the rest of tacrines, the BBB overpassing capacity was measured in silico, taking into account several parameters that could be an indication of their capacity to pass this barrier, such as PSA and QPLogBBB. QPT4 (Figure 3) had a PSA of $100 \AA^{2}$ for each enantiomer and compound KT2 (Figure 7) had a PSA of $107 \AA^{2}$ for each enantiomer, much higher than the required value of less than $60 \AA^{2}$ required for drugs acting in the CNS.

The pharmacological properties of the tacrines presented in this review pave the way for designing tacrine analogues with higher inhibition potency against ChEs, better neuroprotective and antioxidant power, able to permeate the $\mathrm{BBB}$ and with superior pharmacokinetic properties.

To sum up, we are convinced that tacrine is still a reference for designing new, simple and easily available drugs for $A D$ therapy, showing no hepatotoxic effects, and being able to modulate diverse biological targets involved in the progress and evolution of $\mathrm{AD}$. For this reason, multitarget small tacrines are obviously the type of ligands to be considered for any future perspective on this arena. In particular, the synthesis of tacrines resulting from the juxtaposition with other standards, such as antioxidant ferulic or lipoic acid, and melatonin, or natural products, such as neocryptolepine, as it has been shown here, offer clear opportunities for the identification of new molecules showing improved biological properties respect to the reference ligands for the potential therapy of $\mathrm{AD}$.

\section{Acknowledgements}

ÓB-A thanks Comunidad de Madrid and Universidad de Alcalá for a postdoctoral fellowship ("Atracción Talento"). DDI thanks the Spanish Ministry of Science, Innovation and Universities for pre-doctoral FPU grant.

\section{References}

[1] C. Bouza, G. Martínez-Alés, T. López-Cuadrado, PLoS One 2019, 14, e0212196.

[2] E. L. Sampson, M. R. Blanchard, L. Jones, A. Tookman, M. King, Br. J. Psychiatry 2009, 195, 61-66.

[3] R. Guijarro, C. M. San Román, R. Gómez-Huelgas, A. Villalobos, M. Martín, M. Guil, M.-Á. Martínez-González, J. B. Toledo, Neuroepidemiology 2010, 35, 101-108.

[4] A. Marengoni, S. Corrao, A. Nobili, M. Tettamanti, L. Pasina, F. Salerno, A. Iorio, M. Marcucci, F. Bonometti, P. M. Mannucci, Int. J. Geriatr. Psychiatry 2011, 26, 930-936.
[5] E. Perry, R. Perry, G. Blessed, B. Tomlinson, Lancet 1977, 309, 189.

[6] P. T. Francis, A. M. Palmer, M. Snape, G. K. Wilcock, J. Neurol. Neurosurg. Psychiatry 1999, 66, 137-147.

[7] E. K. Perry, R. H. Perry, P. H. Gibson, G. Blessed, B. E. Tomlinson, Neurosci. Lett. 1977, 6, 85-89.

[8] W. Velde, F. Stam, J. Am. Geriatr. Soc. 1976, 24, 12.

[9] P. White, M. J. Goodhardt, J. P. Keet, C. R. Hiley, L. H. Carrasco, I. E. I. Williams, D. M. Bowen, Lancet 1977, 309, 668-671.

[10] P. Davies, Lancet 1976, 308, 1403.

[11] W. K. Summers, L. V. Majovski, G. M. Marsh, K. Tachiki, A. Kling, N. Engl. J. Med. 1986, 315, 1241-1245.

[12] A. Haake, K. Nguyen, L. Friedman, B. Chakkamparambil, G. T. Grossberg, Expert Opin. Drug Saf. 2020, 19, 147-157.

[13] B. Dubois, M. Chupin, H. Hampel, S. Lista, E. Cavedo, B. Croisile, G. L. Tisserand, J. Touchon, A. Bonafee, P. J. Ousset, A. A. Ameur, O. Rouaud, F. Ricolfi, A. Vighetto, F. Pasquier, C. Delmaire, M. Ceccaldi, N. Girard, C. Dufouil, S. Lehericy, I. Tonelli, F. Duveau, O. Colliot, L. Garnero, M. Sarazin, D. Dormont, Alzheimer's Dementia 2015, 11, 1042-1049.

[14] N. C. Inestrosa, A. Alvarez, C. A. Pérez, R. D. Moreno, M. Vicente, C. Linker, O. I. Casanueva, C. Soto, J. Garrido, Neuron 1996, 16, 881-891.

[15] M. J. Oset-Gasque, J. Marco-Contelles, ACS Chem. Neurosci. 2018, 9, 401-403.

[16] R. León, A. G. Garcia, J. Marco-Contelles, Med. Res. Rev. 2013, 33, 139-189.

[17] M. Benchekroun, M. Bartolini, J. Egea, A. Romero, E. Soriano, M. Pudlo, V. Luzet, V. Andrisano, M.-L. Jimeno, M. G. López, S. Wehle, T. Gharbi, B. Refouvelet, L. de Andrés, C. HerreraArozamena, B. Monti, M. L. Bolognesi, M. I. RodríguezFranco, M. Decker, J. Marco-Contelles, L. Ismaili, ChemMedChem 2015, 10, 523-539.

[18] M. L. Bolognesi, A. Cavalli, L. Valgimigli, M. Bartolini, M. Rosini, V. Andrisano, M. Recanatini, C. Melchiorre, J. Med. Chem. 2007, 50, 6446-6449.

[19] A. Cavalli, M. L. Bolognesi, A. Minarini, M. Rosini, V. Tumiatti, M. Recanatini, C. Melchiorre, J. Med. Chem. 2008, 51, 347-72.

[20] A. Romero, J. Marco-Contelles, Curr. Top. Med. Chem. 2017, $17,3328-3335$.

[21] M. J. Oset-Gasque, J. Marco-Contelles, Curr. Top. Med. Chem. 2017, 17, 3349-3360.

[22] C. de los Ríos, J. Marco-Contelles, Eur. J. Med. Chem. 2019, 166, 381-389.

[23] M. Bartolini, J. Marco-Contelles, Chem. Rec. 2019, 19, 927937.

[24] J. Marco-Contelles, E. Pérez-Mayoral, A. Samadi, M. do C Carreiras, E. Soriano, Chem. Rev. 2009, 109, 2652-2671.

[25] A. Samadi, C. Valderas, C. de los Ríos, A. Bastida, M. Chioua, L. González-Lafuente, I. Colmena, L. Gandía, A. Romero, L. del Barrio, M. D. Martín-de-Saavedra, M. G. López, M. Villarroya, J. Marco-Contelles, Bioorg. Med. Chem. 2011, 19, 122133.

[26] J. Marco-Contelles, R. León, C. de los Ríos, A. Samadi, M. Bartolini, V. Andrisano, O. Huertas, X. Barril, F. J. Luque, 
M. I. Rodríguez-Franco, B. López, M. G. López, A. G. García, M. do Carmo Carreiras, M. Villarroya, J. Med. Chem. 2009, 52, 2724-2732.

[27] A. Samadi, J. Marco-Contelles, E. Soriano, M. Álvarez-Pérez, M. Chioua, A. Romero, L. González-Lafuente, L. Gandía, J. M. Roda, M. G. López, M. Villarroya, A. G. García, C. de los Ríos, Bioorg. Med. Chem. 2010, 18, 5861-5872.

[28] O. Trott, A. J. Olson, J. Comput. Chem. 2010, 31, 455-461.

[29] F. Denizot, R. Lang, J. Immunol. Methods 1986, 89, 271-277.

[30] M. Chioua, E. Serrano, Y. Dgachi, H. Martin, D. Jun, J. Janockova, V. Sepsova, O. Soukup, I. Moraleda, F. Chabchoub, L. Ismaili, I. Iriepa, J. Marco-Contelles, ChemistrySelect 2018, 3, 461-466.

[31] G. L. Ellman, K. D. Courtney, V. Andres Jr, R. M. Featherstone, Biochem. Pharmacol. 1961, 7, 88-95.

[32] H. Lineweaver, D. Burk, J. Am. Chem. Soc. 1934, 56, 658-666.

[33] B. Ou, M. Hampsch-Woodill, R. L. Prior, J. Agric. Food Chem. 2001, 49, 4619-4626.

[34] A. Dávalos, C. Gómez-Cordovés, B. Bartolomé, J. Agric. Food Chem. 2004, 52, 48-54.

[35] E. Ramos, A. Palomino-Antolín, M. Bartolini, I. Iriepa, I. Moraleda, D. Diez-Iriepa, A. Samadi, C. V. Cortina, M. Chioua, J. Egea, A. Romero, J. Marco-Contelles, Molecules 2019, 24, 1503.

[36] J. Patocka, D. Jun, K. Kuca, Curr. Drug Metab. 2008, 9, 332335.

[37] C. A. Lipinski, F. Lombardo, B. W. Dominy, P. J. Feeney, $A d v$. Drug Delivery Rev. 1997, 23, 3-25.

[38] H. Boulebd, L. Ismaili, H. Martin, A. Bonet, M. Chioua, J. Marco Contelles, A. Belfaitah, Future Med. Chem. 2017, 9, 723-729.

[39] Y. Dgachi, H. Martin, R. Malek, D. Jun, J. Janockova, V. Sepsova, O. Soukup, I. Iriepa, I. Moraleda, E. Maalej, M. C.
Carreiras, B. Refouvelet, F. Chabchoub, J. Marco-Contelles, L. Ismaili, J. Enzyme Inhib. Med. Chem. 2019, 34, 163-170.

[40] D.-M. Du, P. R. Carlier, Curr. Pharm. Des. 2004, 10, 31413156.

[41] D. M.-T. Camps, P. Camps, Curr. Med. Chem. 2006, 13, 399422.

[42] Y.-P. Pang, P. Quiram, T. Jelacic, F. Hong, S. Brimijoin, J. Biol. Chem. 1996, 271, 23646-23649.

[43] J. E. Biggs-Houck, A. Younai, J. T. Shaw, Curr. Opin. Chem. Biol. 2010, 14, 371-382.

[44] A. Dömling, W. Wang, K. Wang, Chem. Rev. 2012, 112, 3083-3135.

[45] E. Ramos, J. Egea, C. de los Ríos, J. Marco-Contelles, A. Romero, Future Med. Chem. 2017, 9, 765-780.

[46] M. Benchekroun, A. Romero, J. Egea, R. León, P. Michalska, I. Buendía, M. L. Jimeno, D. Jun, J. Janockova, V. Sepsova, O. Soukup, O. M. Bautista-Aguilera, B. Refouvelet, O. Ouari, J. Marco-Contelles, L. Ismaili, J. Med. Chem. 2016, 59, 99679973.

[47] M. Rosini, V. Andrisano, M. Bartolini, M. L. Bolognesi, P. Hrelia, A. Minarini, A. Tarozzi, C. Melchiorre, J. Med. Chem. 2005, 48, 360-363.

[48] L. Wang, I. Moraleda, I. Iriepa, A. Romero, F. López-Muñoz, M. Chioua, T. Inokuchi, M. Bartolini, J. Marco-Contelles, MedChemComm 2017, 8, 1307-1317.

[49] M. H. M. Sharaf, P. L. Schiff Jr, A. N. Tackie, C. H. Phoebe Jr, G. E. Martin, J. Heterocycl. Chem. 1996, 33, 239-243.

Manuscript received: September 4, 2020

Revised manuscript received: October 19, 2020

Version of record online: November 10, 2020 